\title{
Review \\ The Emerging Role of Extracellular Vesicles in Endocrine Resistant Breast Cancer
}

\author{
Giusi La Camera ${ }^{1,+}$, Luca Gelsomino ${ }^{1,+}{ }^{,}$, Amanda Caruso ${ }^{1}$, Salvatore Panza ${ }^{1}$, Ines Barone ${ }^{1}(\mathbb{D}$, \\ Daniela Bonofiglio $^{1,2} \mathbb{0}$, Sebastiano Andò ${ }^{1,2}$, Cinzia Giordano ${ }^{1,2, *, \ddagger}$ and Stefania Catalano ${ }^{1,2, *, \ddagger}$
}

1 Department of Pharmacy, Health and Nutritional Sciences, University of Calabria, Via P. Bucci, 87036 Arcavacata di Rende, CS, Italy; lcmgsi93e44d086t@studenti.unical.it (G.L.C.); luca.gelsomino@unical.it (L.G.); crsmnd96t42d086q@studenti.unical.it (A.C.); salvatore.panza@unical.it (S.P.); ines.barone@unical.it (I.B.); daniela.bonofiglio@unical.it (D.B.); sebastiano.ando@unical.it (S.A.)

2 Centro Sanitario, University of Calabria, Via P. Bucci, 87036 Arcavacata di Rende, CS, Italy

* Correspondence: cinzia.giordano@unical.it (C.G.); stefania.catalano@unical.it (S.C.); Tel.: +39-0984-496216 (C.G.); +39-0984-496207 (S.C.)

+ These authors contributed equally to this work.

$\ddagger$ Joint senior authors.

Citation: La Camera, G.; Gelsomino, L.; Caruso, A.; Panza, S.; Barone, I.; Bonofiglio, D.; Andò, S.; Giordano, C.; Catalano, S. The Emerging Role of Extracellular Vesicles in Endocrine Resistant Breast Cancer. Cancers 2021, 13, 1160. https://doi.org/10.3390/ cancers 13051160

Academic Editors:

Christos Papadimitriou,

Dimitrios Mavroudis and

Nicholas Pavlidis

Received: 4 February 2021

Accepted: 4 March 2021

Published: 8 March 2021

Publisher's Note: MDPI stays neutral with regard to jurisdictional claims in published maps and institutional affiliations.

Copyright: (c) 2021 by the authors. Licensee MDPI, Basel, Switzerland. This article is an open access article distributed under the terms and conditions of the Creative Commons Attribution (CC BY) license (https:// creativecommons.org/licenses/by/ $4.0 /)$.
Simple Summary: Two-thirds of breast cancer patients present an estrogen receptor-positive tumor at diagnosis, and the main treatment options for these patients are endocrine therapies such as aromatase inhibitors, selective modulators of estrogen receptor activity or selective estrogen receptor down-regulators. Although endocrine therapies have high efficacy in early-stage breast cancers, the failure of the therapeutic response to these hormonal treatments remains the major clinical challenge. Recently, extracellular vesicles (EVs) have emerged as a novel mechanism of drug resistance. Indeed, EVs isolated from tumor and stromal cells act as key messengers in intercellular communications able to propagate traits of resistance and/or educate the microenvironment to sustain a breast cancer resistant phenotype. Understanding the EV-mediated molecular mechanisms involved in hormonal resistance can provide the rationale for novel and effective treatment modalities and allow for the identification of potential biomarkers to monitor therapy response in ER-positive breast cancer patients.

Abstract: Breast cancer is the most common solid malignancy diagnosed in females worldwide, and approximately $70 \%$ of these tumors express estrogen receptor $\alpha(E R \alpha)$, the main biomarker of endocrine therapy. Unfortunately, despite the use of long-term anti-hormone adjuvant treatment, which has significantly reduced patient mortality, resistance to the endocrine treatments often develops, leading to disease recurrence and limiting clinical benefits. Emerging evidence indicates that extracellular vesicles (EVs), nanosized particles that are released by all cell types and responsible for local and systemic intercellular communications, might represent a newly identified mechanism underlying endocrine resistance. Unraveling the role of EVs, released by transformed cells during the tumor evolution under endocrine therapy, is still an open question in the cancer research area and the molecular mechanisms involved should be better defined to discover alternative therapeutic approaches to overcome resistance. In this review, we will provide an overview of recent findings on the involvement of EVs in sustaining hormonal resistance in breast cancer and discuss opportunities for their potential use as biomarkers to monitor the therapeutic response and disease progression.

Keywords: breast cancer; endocrine resistance; extracellular vesicles; exosomes; targeted therapies

\section{Introduction}

Breast cancers are heterogeneous and dynamic diseases classified into molecularly distinct subtypes based on the expression of estrogen receptor (ER), progesterone receptor (PR) and human epidermal growth factor receptor 2 (HER2), which influence the clinical 
outcomes and the therapeutic approaches [1]. Approximately two-thirds of all breast cancers express the ER (ER-positive) and depend on its functionality for their proliferation and survival. ER is a member of the nuclear hormone receptor superfamily that, as a ligand-activated transcription factor, regulates the expression of target genes by binding with specific estrogen response elements (EREs), termed "classical" genomic activity [2]. However, estrogen binding to the receptor can also activate different molecular mechanisms termed "nonclassical" ER-mediated transcriptional regulation [3-5]. This occurs via ERE-independent signaling in which ER interacts with other transcription factors, such as activator protein-1 (AP-1), specificity protein 1 (Sp1) and nuclear factor- $\mathrm{kB}$ (NF- $\mathrm{kB}$ ), thus modulating downstream gene expression [3,4]. Moreover, ER activity can be mediated in a ligand-independent manner by a functional cross-talk with growth factor (GF) signaling pathways able to induce post-transcriptional ER modifications (e.g., phosphorylation, acetylation, methylation) that in turn regulate receptor activity [6-8]. Considering the crucial role of the estrogen/ER axis in breast cancer biology, the endocrine-based therapies are currently the primary treatment used in ER-positive breast cancer patients. The therapies include inhibitors of the aromatase enzyme (AIs, e.g., anastrozole, letrozole and exemestane), selective ER modulators (SERMs, e.g., tamoxifen and raloxifene) or selective ER downregulators (SERDs, e.g., fulvestrant) $[9,10]$. Endocrine therapies have high efficacy in early-stage breast cancers, and clinical benefit is achieved in about $50 \%$ of metastatic tumors $[11,12]$. However, despite the high sensitivity of ER-positive breast cancer subtypes to endocrine therapies, a large number of patients result resistant to these therapeutic interventions, experiencing disease recurrence either during or after completion of treatments [10]. Although several mechanisms have been proposed to contribute to the emergence of resistant phenotypes, the complete characterization of the drivers of endocrine resistance in breast cancer is still an open question to explore [13].

Recently, it has become apparent that secreted extracellular vesicles (EVs), as key determinants of cell-to-cell communication, play a pleiotropic role in a wide variety of physiological and pathological processes, including carcinogenesis. EVs are nanosized particles, enclosed within a phospholipid bilayer membrane, that based on their size and cellular origin can be divided into subgroups of "small" vesicles, called exosomes, vesicles that are slightly larger (microvesicles/ectosomes) and apoptotic bodies [14,15]. EVs, released both by normal and neoplastic cells are able to modulate the phenotypic behavior of recipient cells by transferring their genetic and molecular cargo. Current research reported that EVs regulate the complex intercellular pathways involved in breast cancer tumorigenesis from tumor initiation and progression towards metastatic disease and drug resistance [16]. Indeed, data from pre-clinical and clinical specimens' studies indicate that EVs secreted from both tumor and stromal cells through their functional cargo (proteins, mRNAs, miRNAs, DNAs) contribute to breast cancer drug resistance, regulating several processes, including cell survival, epithelial-mesenchymal transition, a stem-like phenotype, education of the tumor microenvironment and drug metabolism $[17,18]$. Therefore, understanding the EV-mediated molecular mechanisms and signaling pathways that promote therapy resistance and identifying potential biomarkers to predict and monitor the therapeutic response are necessary for a more effective breast cancer treatment.

Here, we will review the emerging data in understanding the role of EVs in the mechanisms of resistance to endocrine manipulation and to the alternative strategies implemented to overcome endocrine resistance in ER-positive breast cancer. Given the lack of standardized nomenclature and isolation protocols for a large family of vesicles, we will use the term EVs to refer to this heterogeneous population throughout this review.

\section{Overview of Extracellular Vesicles}

Extracellular vesicles (EVs) are multi-signal messengers naturally released by all cell types into the extracellular space that can be recovered from common biological fluids, such as blood, urine, breast milk, seminal fluids, saliva and malignant effusion [19-24]. Initially observed in plasma by Chargaff and West in 1946 as platelet-derived particles and then 
described by Wolf in 1967 as "platelet dust", the EVs are now well recognized as key players in intercellular communication in both physiological and pathological conditions. The generic name "extracellular vesicles" defines a large population of lipid bilayer-enclosed extracellular structures that can be classified on their physical and biochemical characteristics, cellular source and biogenesis pathways. Based on the "Minimal Information for Studies of Extracellular Vesicles" (MISEV) guidelines [15,25], the EV population can be divided into subgroups of "small" vesicles/exosomes, microvesicles/ectosomes and apoptotic bodies. Particularly, microvesicles (MVs) and exosomes are the two major subtypes of EVs that have received considerable attention in recent years for their ability to induce phenotypic reprogramming in recipient cells [26]. MVs or ectosomes represent the larger EV population (100-1000 $\mathrm{nm}$ in diameter) that bud directly from the plasma membrane. Exosomes, the smallest subtype of EVs (30-150 nm in diameter) generated within endocytic compartments, are secreted into the extracellular space after the fusion of multivesicular bodies (MVBs) with the plasma membrane. Exosome biogenesis can be driven by the activity of the Endosomal Sorting Complex Required for Transport (ESCRT) machinery $[27,28]$, and many pieces of evidence also suggest the existence of an ESCRT-independent pathway that involves tetraspanins, lipids and RabGTPases [29]. The mechanism of EV biogenesis can be modulated by different extracellular conditions, such as hypoxia, the Ca2+-dependent pathway, growth factors and adipokines [30-33]. EV cargo is composed of a common subset of proteins involved in membrane transport and fusion processes, such as Rab GTPases, annexin, tetraspanins (CD9, CD63, CD81), integrins, adhesion molecules, heat shock proteins, enzymes, matrix metalloproteinases, glycoprotein receptors and immune regulator molecules (MCH-I and -II), but also includes selected proteins, lipids and nucleic acids that reveal the unique molecular signature of the cells of origin [29,34].

The release of EVs is increased in cancer $[35,36]$. Particularly, it has been reported in breast cancer that the secretion of EVs was significantly higher in transformed cells than in normal mammary epithelial cells [37]. Similarly, analysis of particle concentration revealed an increase in EV number in the plasma of patients with stage I-IV breast cancer compared to healthy control subjects, while no significant differences were found between the EV number of "in situ" breast cancer and the control group [38]. More recently, Stevic et al. reported an increased amount of vesicles in blood samples of women with Triple Negative Breast Cancer compared to the number of vesicles in plasma samples from healthy women [39]. Overall, these findings suggest the possibility that more aggressive breast cancers could release a large amount of vesicles, but the comparison between the amounts of circulating EVs at different stages of disease should be better defined and deserves more investigations. Breast tumor-derived EVs have been reported to have a role in all cancer hallmarks controlling a wide range of pathways and regulating gene expression by transferring their intra-vesicular content (proteins, lipids, enzymes, metabolites, DNA, mRNA, miRNA, long and short non-coding RNA) into recipient cells [40]. In addition to regulating invasion, vessel formation, pre-metastatic niche preparation, and immune surveillance escape, the bioactive molecules carried by EVs have been proposed as important players in the mechanisms of resistance to therapeutic treatments [41,42] and might represent promising candidate biomarkers for breast cancers [43,44].

\section{EVs and Therapeutic Resistance in ER-Positive Breast Cancer}

Endocrine-targeted treatments represent the mainstay of the standard care both in the adjuvant and recurrent settings of ER-positive breast cancer patients. However, the reduction in the effectiveness of endocrine regimens is one of the major obstacles to successful treatment and still represents an essential clinical challenge for the management of ER-positive disease. Commonly, resistance has been classified into primary (or "de novo" resistance), where insensitivity already exists before treatment, and secondary (or acquired resistance) that develops in patients initially responding to endocrine therapy. The mechanisms of endocrine resistance in breast cancer are very complex and a plethora of molecules and escape signaling pathways have been involved [45,46]. Endocrine insensitivity due 
to the loss of ER expression has been reported in less than $20 \%$ of metastatic breast cancers $[47,48]$, while the majority of endocrine-resistant tumors still retain the ER expression and activity during the development of resistance [49,50]. Indeed, ER signaling primarily mediated by ligand-independent receptor activation [51], remains crucial in mediating resistance. Several mechanisms are responsible of sustaining ER activity in resistance including: (i) an increased expression of the receptor itself [52]; (ii) the gain of function mutations in ESR1 gene [53-58]; (iii) an altered interaction of the receptor with coregulators (coactivators and/or corepressors) [59-61]; (iiii) an increased bidirectional cross-talk between ER and growth factor receptor/oncogenic kinase signaling pathways [62]. In addition, growth factor signaling can contribute to the transcriptional repression of ER gene expression resulting in endocrine resistance [63-65]. The main described mechanisms involved in these molecular events are summarized in Figure 1.

Furthermore, resistance to endocrine therapies could be associated with the development of cellular characteristics similar to those of cells undergoing epithelial-to-mesenchymal transition (EMT) [66], with cells expressing a cancer stem-like phenotype [67,68], or remaining dormant in a quiescence state for a long time in the body before re-awakening [69]. Indeed, it has been demonstrated that dormant cells express features that support their survival despite anti-proliferative endocrine therapy [70]. Moreover, a growing amount of evidence supports the concept that extrinsic resistance might arise from the interplay between tumor cells and several components of the tumor microenvironment, including cancer-associated fibroblasts (CAFs), inflammatory and immune cells, extracellular matrix (ECM), soluble factors and EVs [71-73]. Despite the advances in the knowledge of resistance mechanisms, recently the clinic-genomic characterization of endocrine-resistant advanced breast cancer revealed the lack of a known mechanism of resistance to hormonal therapy in $60 \%$ of analyzed tumors [13]. Nowadays, it has become increasingly clear that EV-mediated cell communication represents a new identified mechanism underlying endocrine resistance. The key findings outlined by the current literature in this field are summarized in Table 1.

Table 1. Mechanisms underlying endocrine resistance in breast cancer mediated by extracellular vesicles (EVs).

\begin{tabular}{|c|c|c|c|c|c|}
\hline Source of EVs & EV Types & Molecules & Type of Resistance & Effects & Ref. \\
\hline MCF-7 cells & Exosomes & Unknown & Tamoxifen & $\begin{array}{l}\text { Decreased ER } \alpha \text { activity, increased of } \\
\text { Akt, AP-1, NF-kB and SNAIL1 activity }\end{array}$ & {$[74,75]$} \\
\hline MCF-7-LTED cells & Exosomes & Unknown & Aromatase inhibitors & $\begin{array}{l}\text { Increased exosome release from } \\
\text { resistant cells }\end{array}$ & [76] \\
\hline TAMR-MCF-7 cells & Exosomes & $\mathrm{miR}-221 / 222$ & Tamoxifen & Decreased P27 and ER $\alpha$ expression & [77] \\
\hline CAFs & MVs & $\operatorname{miR}-221$ & Fulvestrant & Increased CSC population & [78] \\
\hline LCC2 cells & Exosomes & lncRNA UCA1 & Tamoxifen & $\begin{array}{l}\text { Increased cell viability, reduced } \\
\text { apoptosis }\end{array}$ & [79] \\
\hline TAMR-MCF-7 cells & sEVs & Unknown & Tamoxifen & Increased cell migration & [80] \\
\hline CAFs & EVs & mtDNA & Fulvestrant & $\begin{array}{c}\text { Promoted escape from metabolic } \\
\text { quiescence, increased CSC } \\
\text { self-renewal }\end{array}$ & [81] \\
\hline $\begin{array}{c}\text { BT474 cells } \\
\text { Serum of BC patients }\end{array}$ & Exosomes & Unknown & Trastuzumab & $\begin{array}{l}\text { Reduced HER-2 monoclonal antibody } \\
\text { bioavaibility }\end{array}$ & [82] \\
\hline $\begin{array}{l}\text { Serum of HER-2-positive } \\
\text { BC patients }\end{array}$ & EVs & TGF- $\beta 1$, PD-L1 & Trastuzumab & Increased immune evasion & [83] \\
\hline Serum of $B C$ patients & Exosomes & lncRNA SNHG14 & Trastuzumab & Reduced apoptosis & [84] \\
\hline BT474-TR cells & Exosomes & $\begin{array}{c}\text { lncRNA } \\
\text { AGAP2-AS1 }\end{array}$ & Trastuzumab & $\begin{array}{l}\text { Inhibited trastuzumab-induced cell } \\
\text { cytotoxicity }\end{array}$ & [85] \\
\hline BT474-TR cells & Exosomes & $\begin{array}{l}\text { lncRNA } \\
\text { AFAP1-AS1 }\end{array}$ & Trastuzumab & Increased $E R B B 2$ gene translation & [86] \\
\hline BT474 cells & Exosomes & $\operatorname{miR}-567$ & Trastuzumab & Reversed trastuzumab resistance & [87] \\
\hline
\end{tabular}


Table 1. Cont.

\begin{tabular}{cllcc}
\hline \multicolumn{1}{c}{ Source of EVs } & EV Types & Molecules & $\begin{array}{c}\text { Type of } \\
\text { Resistance }\end{array}$ & Effects \\
\hline MCF-7 cells T47D cells & Exosomes & miR-432-5p & Palbociclib & $\begin{array}{c}\text { Promoted suppression of TGF- } \beta \\
\text { pathway }\end{array}$ \\
\hline
\end{tabular}

EVs, extracellular vesicles; MVs, microvesicles; sEVs, small extracellular vesicles; ER $\alpha$, estrogen receptor $\alpha$; AP-1, activation protein-1; NF$\mathrm{kB}$, nuclear factor- $\mathrm{kB}$; SNAIL1, snail homolog 1; MCF-7-LTED, MCF-7 long-term estrogen-deprived; P27, cyclin-dependent kinase inhibitor P27; TAMR-MCF-7, tamoxifen-resistant MCF-7; CSCs, cancer stem cell-like; CAFs, cancer-associated fibroblasts; LCC2, tamoxifen-resistant subline of the MCF-7 human breast cancer cell; BC, breast cancer; lncRNA UCA1, long non-coding RNA urothelial cancer associated 1; mtDNA, mitochondrial DNA; TGF- $\beta 1$, transforming growth factor beta 1; PD-L1, programmed death-ligand 1; SNHG14, small nucleolar RNA host gene 14; AGAP2-AS1, AGAP2- antisense RNA1; AFAP1-AS1, actin filament-associated protein 1 antisense RNA1; ERBB2, human epidermal growth factor receptor 2; miR, microRNA; BT474-TR, BT47D trastuzumab resistant.

\subsection{EVs and Hormonal Resistance}

Semina et al. initially found that co-culturing estrogen-dependent MCF-7 breast cancer cells with the MCF-7 cell line resistant to tamoxifen (MCF7/T) induced horizontal hormone resistance in hormone-sensitive cells as a result of intercellular interaction, suggesting the possible involvement of EVs in the progression of hormonal resistance [74]. More recently, the same authors demonstrated that long-term treatment of MCF-7 breast cancer cells with EVs from MCF7/T caused the partial resistance of sensitive cells to this antiestrogen. These effects were associated with a decreased ER $\alpha$ activity along with an activation of transcriptional factors involved in growth, apoptosis and EMT processes, such as AP-1, NF- $\mathrm{BB}$ and SNAIL1 in both the primary resistant cells and the cells with the EV-induced resistance. Besides, a marked increase in the expression and activity of Akt in all of the resistant cells compared to the parental MCF-7 cells was shown, and exposure to a PI3K inhibitor prevented the EV-induced resistance, highlighting the involvement of PI3K/Akt signaling in the EV-transferring resistance [75]. Recently, it has been shown that in the MCF-7-LTED (Long-Term Estrogen-Deprived) subline, modelling resistance to Aromatase Inhibitors (AIs) is associated with an enhanced EV production, which appears to be related to an increased Rab GTPase expression. Quantitative proteomic analysis showed an enrichment of proteins frequently identified in vesicles in MCF-7-LTED compared to MCF7 cells. Interestingly, the most up-regulated proteins in MCF-7-LTED cells belong to the Rab GTPase family, important regulators of vesicle biogenesis and secretion in cancer [76].

EVs, released by both tumor and stromal cells, can confer resistance to therapysensitive cancer cells by transmitting miRNAs, and small non-coding post-transcriptional regulators of gene expression miRNAs can accumulate in EVs, where they are protected from cleavage by RNAses in the blood [89]. EVs released from tamoxifen-resistant MCF7 cells by transferring miR-221/222 have been reported as a mechanism of tamoxifen resistance. It has been demonstrated that the crucial vesicle component miR-221/222 can effectively reduce expression of their target genes P27 and ER $\alpha$, leading to enhanced tamoxifen resistance [77]. More recently, Sansone et al. demonstrated that CAF-derived EVs, by transferring miR-221 to breast cancer cells, lead to an expansion of the cancer stem cell-like population promoting hormone therapy resistance (HTR). Indeed, they found in patients with HTR metastatic disease a higher expression of miR-221 in circulating EVs compared with healthy controls. Mechanistically, they reported that autocrine IL6/Stat3 signaling contributes to the proliferation of CAFs and to the biogenesis of oncomiR-221 ${ }^{\text {hi }}$ EVs. Interestingly, the depletion of murine CAFs in patient-derived xenografts from breast cancer bone metastases restored sensitivity to HT associated with a reduction in the cancer stem cell-like phenotype. On the contrary, in HT-sensitive cancer cells, both murine and human CAFs induced "de novo" HT resistance through the induction of the Notch-mediated breast cancer stem cell-like phenotype that expressed low levels of ER [78]. The EV-mediated transfer of long non-coding RNA (lncRNA) has been demonstrated as an additional mechanism of tamoxifen resistance. Xu et al. found increased levels of lncRNA urothelial cancer-associated 1 (UCA1) in the tamoxifen-resistant variant of MCF-7, termed LCC2, and also in EVs released from these cells. MCF-7 cells pretreated with EVs/LCC2 
exhibited, after tamoxifen treatment, an enhanced cell viability, a reduced expression of cleaved caspase- 3 and a lower ratio of apoptosis. Knockdown of UCA1 in LCC2 cells clearly indicated that this lncRNA plays a crucial role in inducing tamoxifen-resistance. Indeed, vesicles from UCA1-knockdown LCC2 cells showed a significantly reduced capability to promote tamoxifen resistance in MCF-7 cells [79].

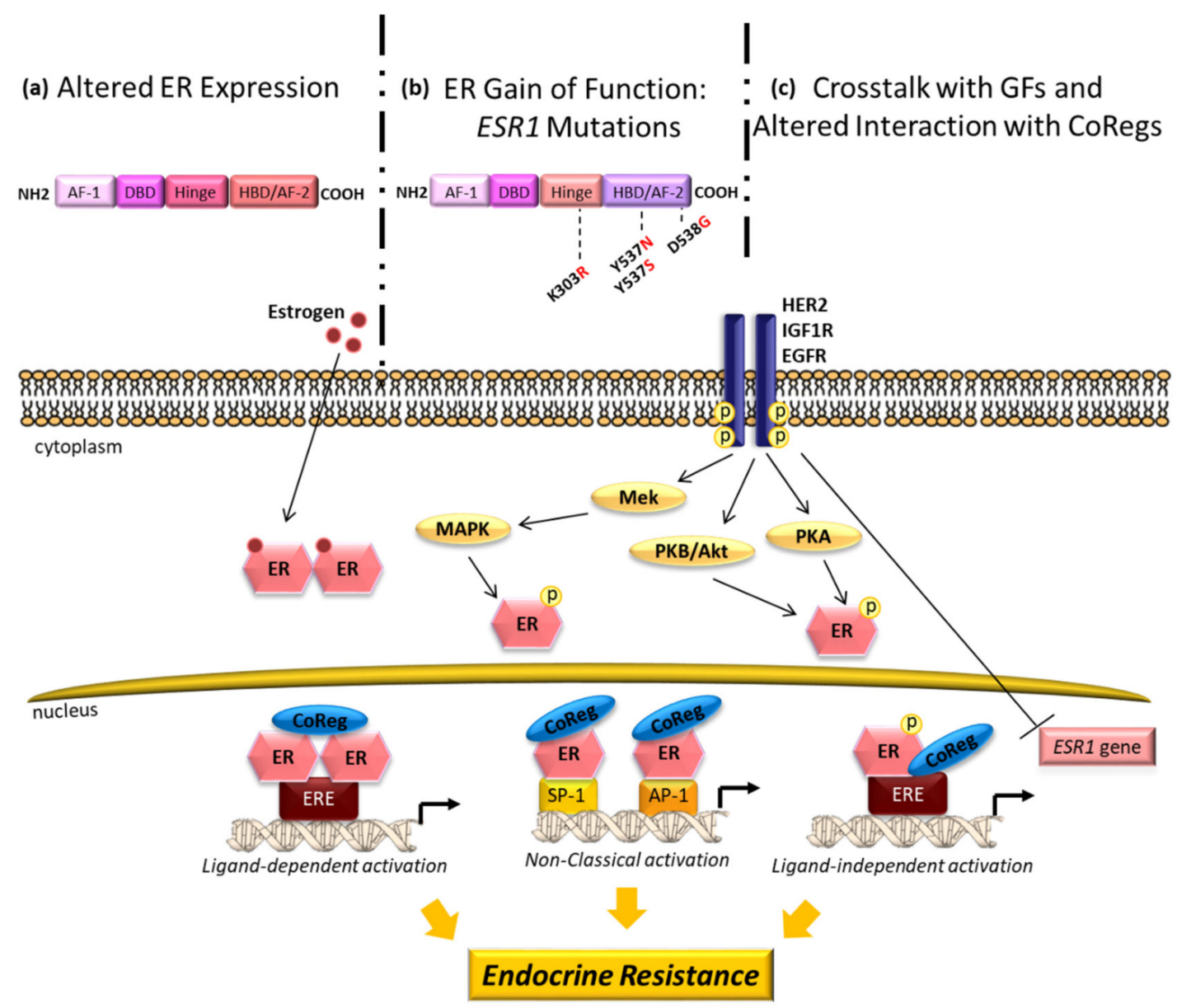

Figure 1. Representation of the main mechanisms sustaining endocrine resistance mediated by estrogen receptor $\alpha$ (ER $\alpha$ ). The structural domains of ER $\alpha$ contain the ligand-independent activation function (AF-1) in the amino-terminal region, a DNA-binding domain (DBD), and a carboxy-terminal hormone-binding domain (HBD), containing the ligand-dependent activation function (AF-2). In the classical ER $\alpha$ activation, estradiol binds to its cognate receptor in the cytoplasm, leading to dimerization, nuclear translocation and interaction with specific DNA sequences (ERE, estrogen responsive element) in target genes (ligand-dependent activation). The ER $\alpha$ can also bind to transcription factors such as activation protein 1 (Ap1) and specificity protein 1 (Sp1) activating gene target transcription (non-classical activation). ER $\alpha$ signaling activation can also occur through second messengers downstream of growth factor signaling pathways (ligand-independent activation). (a) Altered ER $\alpha$ expression including either loss of ER $\alpha$ or increased ER $\alpha$ expression. (b) Gain of function mutations in the ESR1 gene. The most characterized mutations within ER $\alpha$ were reported. The K303R somatic mutation, in the hinge domain, allows ER $\alpha$ to be more highly phosphorylated by Protein Kinase A (PKA) and Protein Kinase B (PKB/Akt), while the Y537N, Y537S, and D538G mutations, in the HBD/AF-2 domain, allow the receptor to be phosphorylated by Mitogen-activated protein kinase (MAPK), resulting in a ligand-independent constitutive activation of the receptor. (c) An increased bidirectional cross-talk between wild-type or mutated ER $\alpha$ and growth factor receptors (epidermal growth factor receptor-EGFR, the human epidermal growth factor receptor 2-HER2, the insulin-like growth factor receptor 1-IGFR 1) induces several downstream phosphorylation events that affect ER $\alpha$ activation, and an altered interaction of ER with coregulators affects ER transcriptional activity in a ligand-independent manner sustaining endocrine resistance. Growth factor signaling can also contribute to endocrine resistance diminishing ESR1 gene expression. 
Several findings have shown that EVs are able to modulate the key steps of the metastatic process [14]. A recent work reported a link between EVs and the P2X purinoreceptor 7 (P2X7) proposing a new mechanism of metastasis in tamoxifen-resistant (TAMR) breast cancer cells. P2X7, a ligand-gated ion channel receptor activated by ATP, is over-expressed in several tumors, including breast cancer, where it is involved in tumor development and metastasis [90-92]. The authors reported that EVs isolated from TAMR-MCF-7 cells increased their own migratory capabilities in a concentration-dependent manner. Moreover, P2X7 antagonist decreased the number of secreted EVs and the protein levels of CD63 in TAMR-MCF-7 cells, highlighting the crucial role of P2X7 in influencing the EV production [80]. Sansone et al. have provided data supporting the hypothesis that the horizontal transfer of mitochondrial DNA (mtDNA) from EVs regulates escape from dormancy in hormonal therapy (HT)-resistant breast cancer leading to metastatic progression. They found the full mitochondrial genome packaged in CAF-derived EVs and in circulating EVs from patients with HT-resistant metastatic disease. Specifically, CAF-derived EVs induced an escape from metabolic quiescence in both HT sensitive cells or HT metabolically dormant populations. The horizontal transfer of mtDNA was observed in cancer stem-like cells and associated with an increased self-renewal potential leading to endocrine therapy resistance [81].

\subsection{EVs and Therapeutic Strategies to Overcome Endocrine Resistance}

Mechanisms of endocrine resistance involve extensive cross-talk between ER and tyrosine kinase growth factor receptors and their downstream signaling pathways. Genetic or epigenetic alterations in various components of the signaling pathways, such as overexpression of human epidermal growth factor receptor 2 (HER2) and aberrant expression of cell-cycle regulators, have been reported. Indeed, it is well established that ongoing endocrine treatment can induce adaptive changes in breast cancer cells resulting in an aberrant activation of growth factor-mediated proliferative and survival pathways such as PI3K (Phosphoinositide 3-Kinase) Akt/mTOR (mechanistic target of rapamycin) and Rat sarcoma viral oncogene (RAS)/Mitogen-activated kinase kinase (MEK)/MAPK which in turn are able to induce an estrogen-independent receptor activation [93]. The benefit of combining endocrine therapy with molecular targeted agents and signal transduction inhibitors has been the major focus of clinical trials to overcome or delay endocrine resistance in ER-positive breast cancer [45].

\subsubsection{EVs and HER2 Targeted Therapy}

Multiple clinical and experimental observations have largely associated the high expression and activation levels of epidermal growth factor receptor family signaling pathways, especially of the HER2, with lower therapeutic efficacy of endocrine therapy [94-97]. The membrane tyrosine kinase ERBB2 gene has been found amplified in $\sim 25 \%$ of ERpositive breast cancer, and clinical evidence revealed that these HER2-positive tumors display the more aggressive behavior of the disease, resistance to hormonal therapy and shorter overall survival [98-101]. These well-established contributions of epidermal growth factor receptor signaling pathways in the development of resistance to endocrine therapies represent the rationale behind combined treatments with endocrine therapy and selective target inhibitors of growth factor signaling pathways [10,102]. Although treatment with the anti-HER2 monoclonal antibody trastuzumab results in a good clinical response in breast cancer patients, not all HER2-overexpressing tumors respond to these therapies and many of these that initially respond later acquire resistance.

Some studies reported the involvement of EVs in promoting resistance to targeted therapy. An initial study demonstrated the possibility that EVs affect sensitivity to HER2targeted therapy "in vitro" and "in vivo". Particularly, it has been found that EVs isolated either from the ER-positive BT474 cell line overexpressing HER2 or in breast cancer patients' serum can directly bind to the anti-HER2 monoclonal antibody trastuzumab and reduce its bioavailability [82]. Another study showed that HER2-targeted drug resistance is correlated 
with an increased amount of transforming growth factor beta 1 (TGF- $\beta 1$ ) and programmed death-ligand 1 (PD-L1) and resistance to the anti-tumor immune response. EVs carrying these molecules can transfer phenotypic traits of cells of origin to drug-sensitive cells, further promoting immune evasion. Moreover, in HER2-positive breast cancer patients, EV-associated TGF- $\beta 1$ levels correlate with response to HER2-targeted therapy, proposing TGF- $\beta 1$ as an EV-associated biomarker to monitor the treatment response [83].

EV transmitted non-coding RNAs may also contribute to the trastuzumab resistance. It has been demonstrated that lncRNA small nucleolar RNA host gene 14 (SNHG14) was upregulated in trastuzumab-resistant ER-positive breast cancer cells. Extracellular lncRNASNHG14 was able to be incorporated into vesicles, transferred to sensitive cells and induce trastuzumab resistance by targeting $\mathrm{Bcl}-2$ /Bax signaling and thus inhibiting cell apoptosis. Furthermore, the expression level of SNHG14 in circulating EVs was increased in patients who exhibited resistance to trastuzumab, compared with those exhibiting a response, suggesting lncRNA-SNHG14 in serum vesicles as a potential diagnostic biomarker for breast cancer [84]. It has also been shown that an enhanced expression of lncRNA AGAP2 antisense RNA 1 (AGAP2-AS1) in transtuzumab-resistant ER-positive breast cancer cells promotes resistance of recipient cancer cells through packaging into vesicles [85]. Similarly, it has been evidenced that IncRNA actin filament-associated protein 1 antisense RNA 1 (AFAP1-AS1) induces trastuzumab resistance through binding with AU-binding factor 1 (AUF1) protein which enhanced the translation of the ERBB2 gene [86]. Moreover, Han et al. utilizing publicly available miRNA expression profiling data of breast cancer, identified miR-567 among the dysregulated miRNAs in trastuzumab-resistant cells. They found that an increased miR-567 expression inhibited autophagy by targeting a key autophagyrelated protein (ATG5), thus reversing trastuzumab resistance of breast cancer, while the knockdown of miR-567 expression induced resistance to anti-HER2 targeted therapy. In addition, extracellular miR-567 is also able to reverse the trastuzumab resistance of recipient cells [87].

\subsubsection{EVs and CDK4/6 Inhibitors}

Since the aberrant expression of cell-cycle regulators that contribute to the loss of cell cycle control [103-106] has been reported as a mechanism of endocrine resistance, the highly selective cyclin-dependent kinases 4/6 (CDK4/6) inhibitors (e.g., palbociclib, ribociclib and abemaciclib) have emerged as powerful agents to overcome endocrine resistance and have been approved in the metastatic setting for ER-positive/HER2-disease [107]. Despite their clinical benefits, the useful biomarkers able to predict the response to these agents are still lacking. Del Re et al. reported that mRNA expression of thymidine kinase 1 (TK1), CDK4, 6 and 9 in plasma-derived vesicles of ER+/HER2-advanced breast cancer patients can predict sensitivity to CDK inhibitor treatments. Particularly, they found that high CDK4 mRNA levels in EVs are associated with the response to combined treatment of palbociclib plus fulvestrant, while high mRNA levels of TK1 and CDK9 in plasma-derived EVs are associated with resistance to palbociclib treatment [108]. Recently, a role for EVs in mediating CDK4/ 6 therapy resistance has also been reported [88]. It has been demonstrated that increased CDK6 expression is a hallmark of acquired resistance to CDK4/ 6 inhibitors and that resistance is conferred through extracellular signalling mediated by EVs. At the molecular level, the authors found that miR-432-5p in EVs transferred from resistant cells to neighboring cells increases CDK6 levels by suppressing the transforming growth factor- $\beta$ pathway via SMAD4 knockdown, allowing cells to overcome G1 arrest [88]. The modalities by which EVs may influence the therapeutic response in ER-positive breast cancers are summarized in Figure 2. 


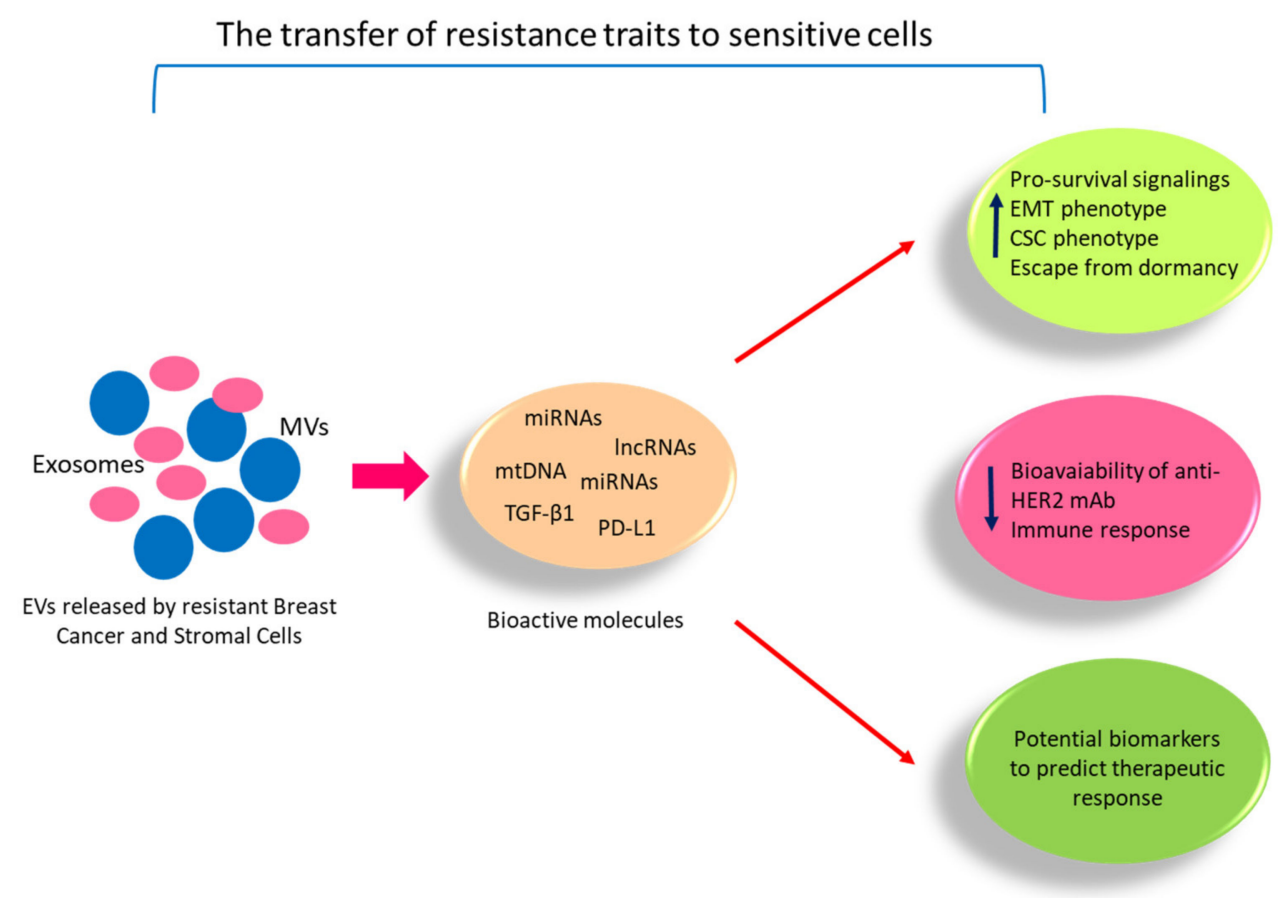

Figure 2. The proposed function of EVs secreted by breast cancer or stromal cells in endocrine treatment resistance. EVs, by transferring their cargo in sensitive breast cancer cells, can confer traits of hormonal resistance by inducing signaling pathways involved in survival, migration, invasion, epithelial mesenchymal transition (EMT), in sustaining the cancer stem cell-like (CSC) phenotype and escape from dormancy. EVs can reduce the bioavailability of anti-HER2 mAb and immune evasion promoting resistance to targeted therapy to overcome endocrine therapies' failure. Finally, evaluation of the molecular cargo of circulating EVs has promising value to discover potential biomarkers to predict the therapeutic response in ER-positive breast cancer patients.

\section{Conclusions}

The occurrence of resistance to endocrine therapy in ER-positive breast cancer patients still represents the major clinical failure. Considerable evidence suggests that EVs generated from tumor cells in response to stress conditions such as therapeutic treatments might communicate pro-survival messages into recipient cells transferring the ability to escape endocrine treatment. Monitoring the changes in the bioactive molecule profiles of the tumorderived EVs during the adaptation to the treatment has the unique potential to depict in real-time the dynamic plasticity of tumor evolution during the acquisition of a resistant phenotype. Thus, increasing our understanding of EV-mediated hormonal resistance in ERpositive breast cancers and the translation of these findings to the clinical application can provide a novel and effective treatment modality for future cancer management. Moreover, EVs seem to have high prospects as a potential liquid biopsy and hold great promise for early diagnosis and staging of breast cancer. However, although the high potential for the clinical use of EVs as molecular markers of disease has been suggested, some issues for routinely working with them still persist due to their high variability in the biological samples, which makes it difficult to establish a clinical cut-off, and the lack of a highly sensitive analytical platforms able to avoid interference from contaminating factors. Thus, to fully translate EV research into clinically reliable tools for cancer therapeutic applications, the development of highly sensitive single tumor-EV detection methods are still necessary. In addition, future pre-clinical studies are required to prove the "in vivo" transfer of resistance by EVs to breast cancer cells along with clinical studies to validate the putative EV markers associated with the endocrine-resistant phenotype. For instance, to address this latter issue, longitudinal evaluation of circulating EVs in a larger set of pre-and post-therapeutic intervention samples may help to define the useful biomarker 
to monitor the evolution of sensitivity to endocrine therapies in women with ER-positive breast cancer.

Given the mounting evidence for the role of EVs in many aspects of breast cancer, biology efforts in this field of cancer research hold great promise.

\section{Review Criteria}

Original articles published in the last two decades have been searched in PubMed, using the following search terms: "extracellular vesicles and breast cancer", "extracellular vesicles and endocrine resistance", "extracellular vesicles and tamoxifen resistance", "extracellular vesicles and aromatase inhibitor resistance", "extracellular vesicles and estrogen receptor down regulators". A similar search was performed using the term exosome instead of extracellular vesicles. Furthermore, additional relevant original articles related to the endocrine resistance mechanisms in breast cancer have been selected. All the articles selected were English-language full-text papers.

Author Contributions: Conceptualization, C.G., S.C.; preparing the manuscript, G.L.C., L.G., C.G., S.C.; collecting data, C.G., G.L.C., A.C., S.P., I.B., D.B.; writing, and editing; G.L.C., L.G., C.G., S.C.; preparing figures and tables, S.P., A.C., I.B., D.B.; contributing to revising the manuscript, S.A., C.G., S.C. All authors have read and agreed to the published version of the manuscript.

Funding: This research was funded by a special award to the Department of Pharmacy, Health and Nutritional Sciences of University of Calabria (Italy) (Department of Excellence, Italian Law 232/2016) from the Italian Ministry of Research and University (MIUR), by the AIRC Investigator Grant (IG) \#21414 and BANDO PRIN 2017 \# 2017EKMFTN_001 to S. Catalano; by BANDO PRIN 2017 \# 2017WNKSLR_005 to I. Barone.

Conflicts of Interest: The authors declare no conflict of interest.

\section{References}

1. Perou, C.M.; Sørlie, T.; Eisen, M.B.; Van De Rijn, M.; Jeffrey, S.S.; Rees, C.A.; Pollack, J.R.; Ross, D.T.; Johnsen, H.; Akslen, L.A.; et al. Molecular portraits of human breast tumours. Nature 2000, 406, 747-752. [CrossRef]

2. Mangelsdorf, D.J.; Thummel, C.; Beato, M.; Herrlich, P.; Schütz, G.; Umesono, K.; Blumberg, B.; Kastner, P.; Mark, M.; Chambon, P.; et al. The nuclear receptor superfamily: The second decade. Cell 1995, 83, 835-839. [CrossRef]

3. Kushner, P.J.; Agard, D.A.; Greene, G.L.; Scanlan, T.S.; Shiau, A.K.; Uht, R.M.; Webb, P. Estrogen receptor pathways to AP-1. J. Steroid Biochem. Mol. Biol. 2000, 74, 311-317. [CrossRef]

4. Schiff, R.; Massarweh, S.A.; Shou, J.; Bharwani, L.; Arpino, G.; Rimawi, M.; Osborne, C.K. Advanced concepts in estrogen receptor biology and breast cancer endocrine resistance: Implicated role of growth factor signaling and estrogen receptor coregulators. Cancer Chemother. Pharmacol. 2005, 56, 10-20. [CrossRef]

5. Klinge, C.M. Estrogen receptor interaction with estrogen response elements. Nucleic Acids Res. 2001, 29, 2905-2919. [CrossRef]

6. Lee, A.V.; Cui, X.; Oesterreich, S. Cross-talk among estrogen receptor, epidermal growth factor, and insulin-like growth factor signaling in breast cancer. Clin. Cancer Res. Off. J. Am. Assoc. Cancer Res. 2001, 7, 4429s-4435s.

7. Cui, Y.; Zhang, M.; Pestell, R.; Curran, E.M.; Welshons, W.V.; Fuqua, S.A. Phosphorylation of Estrogen Receptor $\alpha$ Blocks Its Acetylation and Regulates Estrogen Sensitivity. Cancer Res. 2004, 64, 9199-9208. [CrossRef] [PubMed]

8. Rayala, S.K.; Talukder, A.H.; Balasenthil, S.; Tharakan, R.; Barnes, C.J.; Wang, R.-A.; Aldaz, M.; Khan, S.; Kumar, R. P21-Activated Kinase 1 Regulation of Estrogen Receptor-Activation Involves Serine 305 Activation Linked with Serine 118 Phosphorylation. Cancer Res. 2006, 66, 1694-1701. [CrossRef]

9. Johnston, S.R.; Yeo, B. The Optimal Duration of Adjuvant Endocrine Therapy for Early Stage Breast Cancer-With What Drugs and for How Long? Curr. Oncol. Rep. 2014, 16, 358. [CrossRef] [PubMed]

10. Aggelis, V.; Johnston, S.R.D. Advances in Endocrine-Based Therapies for Estrogen Receptor-Positive Metastatic Breast Cancer. Drugs 2019, 79, 1849-1866. [CrossRef]

11. Early Breast Cancer Trialists' Collaborative Group (EBCTCG); Davies, C.; Godwin, J.; Gray, R.; Clarke, M.; Cutter, D.; Darby, S.; McGale, P.; Pan, H.C.; Taylor, C.; et al. Relevance of breast cancer hormone receptors and other factors to the efficacy of adjuvant tamoxifen: Patient-level meta-analysis of randomised trials. Lancet 2011, 378, 771-784. [CrossRef] [PubMed]

12. Schiavon, G.; Smith, I.E. Endocrine Therapy for Advanced/Metastatic Breast Cancer. Hematol. Clin. N. Am. 2013, 27, 715-736. [CrossRef]

13. Razavi, P.; Chang, M.T.; Xu, G.; Bandlamudi, C.; Ross, D.S.; Vasan, N.; Cai, Y.; Bielski, C.M.; Donoghue, M.T.A.; Jonsson, P.; et al. The Genomic Landscape of Endocrine-Resistant Advanced Breast Cancers. Cancer Cell 2018, 34, 427-438. [CrossRef] [PubMed]

14. Théry, C.; Zitvogel, L.; Amigorena, S. Exosomes: Composition, biogenesis and function. Nat. Rev. Immunol. 2002, 2, 569-579. [CrossRef] 
15. Théry, C.; Witwer, K.W.; Aikawa, E.; Alcaraz, M.J.; Anderson, J.D.; Andriantsitohaina, R.; Antoniou, A.; Arab, T.; Archer, F.; Atkin-Smith, G.K.; et al. Minimal information for studies of extracellular vesicles 2018 (MISEV2018): A position statement of the International Society for Extracellular Vesicles and update of the MISEV2014 guidelines. J. Extracell. Vesicles 2018, 7, 1535750. [CrossRef] [PubMed]

16. Giordano, C.; La Camera, G.; Gelsomino, L.; Barone, I.; Bonofiglio, D.; Andò, S.; Catalano, S. The Biology of Exosomes in Breast Cancer Progression: Dissemination, Immune Evasion and Metastatic Colonization. Cancers 2020, 12, 2179. [CrossRef]

17. Giallombardo, M.; Taverna, S.; Alessandro, R.; Hong, D.; Rolfo, C. Exosome-mediated drug resistance in cancer: The near future is here. Ther. Adv. Med. Oncol. 2016, 8, 320-322. [CrossRef]

18. Ender, F.; Von Bubnoff, N.; Gieseler, F. Extracellular Vesicles: Subcellular Organelles with the Potential to Spread Cancer Resistance. Anticancer Res. 2019, 39, 3395-3404. [CrossRef]

19. Chaparro Padilla, A.; Weber Aracena, L.; Realini Fuentes, O.; Albers Busquetts, D.; Hernandez Rios, M.; Ramirez Lobos, V.; Pascual La Rocca, A.; Nart Molina, J.; Beltran Varas, V.; Acuna-Gallardo, S.; et al. Molecular signatures of extracellular vesicles in oral fluids of periodontitis patients. Oral Dis. 2020, 26, 1318-1325. [CrossRef]

20. Sun, Y.; Huo, C.; Qiao, Z.; Shang, Z.; Uzzaman, A.; Liu, S.; Jiang, X.; Fan, L.Y.; Ji, L.; Guan, X.; et al. Comparative Proteomic Analysis of Exosomes and Microvesicles in Human Saliva for Lung Cancer. J. Proteome Res. 2018, 17, 1101-1107. [CrossRef] [PubMed]

21. Galley, J.D.; Besner, G.E. The Therapeutic Potential of Breast Milk-Derived Extracellular Vesicles. Nutrients 2020, 12,745 [CrossRef] [PubMed]

22. Vojtech, L.; Woo, S.; Hughes, S.; Levy, C.; Ballweber, L.; Sauteraud, R.P.; Strobl, J.; Westerberg, K.; Gottardo, R.; Tewari, M.; et al. Exosomes in human semen carry a distinctive repertoire of small non-coding RNAs with potential regulatory functions. Nucleic Acids Res. 2014, 42, 7290-7304. [CrossRef]

23. Pisitkun, T.; Shen, R.-F.; Knepper, M.A. Identification and proteomic profiling of exosomes in human urine. Proc. Natl. Acad. Sci. USA 2004, 101, 13368-13373. [CrossRef]

24. Hiltbrunner, S.; Mints, M.; Eldh, M.; Rosenblatt, R.; Holmström, B.; Alamdari, F.; Johansson, M.; Veerman, R.E.; Winqvist, O.; Sherif, A.; et al. Urinary Exosomes from Bladder Cancer Patients Show a Residual Cancer Phenotype despite Complete Pathological Downstaging. Sci. Rep. 2020, 10, 5960. [CrossRef] [PubMed]

25. Lötvall, J.; Hill, A.F.; Hochberg, F.; Buzás, E.I.; Di Vizio, D.; Gardiner, C.; Gho, Y.S.; Kurochkin, I.V.; Mathivanan, S.; Quesenberry, P.; et al. Minimal Experimental Requirements for Definition of Extracellular Vesicles and their Functions: A Position Statement from the International Society for Extracellular Vesicles. J. Extracell. Vesicles 2014, 3, 2691. [CrossRef] [PubMed]

26. Raposo, G.; Stoorvogel, W. Extracellular vesicles: Exosomes, microvesicles, and friends. J. Cell Biol. 2013, 200, 373-383. [CrossRef]

27. Katzmann, D.J.; Babst, M.; Emr, S.D. Ubiquitin-Dependent Sorting into the Multivesicular Body Pathway Requires the Function of a Conserved Endosomal Protein Sorting Complex, ESCRT-I. Cell 2001, 106, 145-155. [CrossRef]

28. Henne, W.M.; Buchkovich, N.J.; Emr, S.D. The ESCRT Pathway. Dev. Cell 2011, 21, 77-91. [CrossRef]

29. Anand, S.; Samuel, M.; Kumar, S.; Mathivanan, S. Ticket to a bubble ride: Cargo sorting into exosomes and extracellular vesicles. Biochim. Biophys. Acta Proteins Proteom. 2019, 1867, 140203. [CrossRef] [PubMed]

30. King, H.W.; Michael, M.Z.; Gleadle, J.M. Hypoxic enhancement of exosome release by breast cancer cells. BMC Cancer 2012, 12, 421. [CrossRef] [PubMed]

31. Messenger, S.W.; Woo, S.S.; Sun, Z.; Martin, T.F.J. A Ca2+-stimulated exosome release pathway in cancer cells is regulated by Munc13-4. J. Cell Biol. 2018, 217, 2877-2890. [CrossRef] [PubMed]

32. Giordano, C.; Gelsomino, L.; Barone, I.; Panza, S.; Augimeri, G.; Bonofiglio, D.; Rovito, D.; Naimo, G.D.; Leggio, A.; Catalano, S.; et al. Leptin Modulates Exosome Biogenesis in Breast Cancer Cells: An Additional Mechanism in Cell-to-Cell Communication. J. Clin. Med. 2019, 8, 1027. [CrossRef]

33. Lopatina, T.; Bruno, S.; Tetta, C.; Kalinina, N.; Porta, M.; Camussi, G. Platelet-derived growth factor regulates the secretion of extracellular vesicles by adipose mesenchymal stem cells and enhances their angiogenic potential. Cell Commun. Signal. CCS 2014, 12, 26. [CrossRef] [PubMed]

34. Meldolesi, J. Exosomes and Ectosomes in Intercellular Communication. Curr. Biol. 2018, 28, R435-R444. [CrossRef]

35. Bebelman, M.P.; Smit, M.J.; Pegtel, D.M.; Baglio, S.R. Biogenesis and function of extracellular vesicles in cancer. Pharmacol. Ther. 2018, 188, 1-11. [CrossRef] [PubMed]

36. Khan, S.; Bennit, H.F.; Turay, D.; Perez, M.; Mirshahidi, S.; Yuan, Y.; Wall, N.R. Early diagnostic value of survivin and its alternative splice variants in breast cancer. BMC Cancer 2014, 14, 176. [CrossRef]

37. Riches, A.; Campbell, E.; Borger, E.; Powis, S. Regulation of exosome release from mammary epithelial and breast cancer cells-A new regulatory pathway. Eur. J. Cancer 2014, 50, 1025-1034. [CrossRef] [PubMed]

38. Galindo-Hernandez, O.; Villegas-Comonfort, S.; Candanedo, F.; González-Vázquez, M.-C.; Chavez-Ocaña, S.; Jimenez-Villanueva, X.; Sierra-Martinez, M.; Salazar, E.P. Elevated Concentration of Microvesicles Isolated from Peripheral Blood in Breast Cancer Patients. Arch. Med. Res. 2013, 44, 208-214. [CrossRef]

39. Stevic, I.; Müller, V.; Weber, K.; Fasching, P.A.; Karn, T.; Marmé, F.; Schem, C.; Stickeler, E.; Denkert, C.; Van Mackelenbergh, M.; et al. Specific microRNA signatures in exosomes of triple-negative and HER2-positive breast cancer patients undergoing neoadjuvant therapy within the GeparSixto trial. BMC Med. 2018, 16, 1-16. [CrossRef] [PubMed] 
40. Xavier, C.P.R.; Caires, H.R.; Barbosa, M.A.G.; Bergantim, R.; Guimarães, J.E.; Vasconcelos, M.H. The Role of Extracellular Vesicles in the Hallmarks of Cancer and Drug Resistance. Cells 2020, 9, 1141. [CrossRef] [PubMed]

41. Steinbichler, T.B.; Dudás, J.; Skvortsov, S.; Ganswindt, U.; Riechelmann, H.; Skvortsova, I.I. Therapy resistance mediated by exosomes. Mol. Cancer 2019, 18, 58. [CrossRef]

42. Dong, X.; Bai, X.; Ni, J.; Zhang, H.; Duan, W.; Graham, P.; Li, Y. Exosomes and breast cancer drug resistance. Cell Death Dis. 2020, 11, 987. [CrossRef]

43. Cohen, J.D.; Li, L.; Wang, Y.; Thoburn, C.; Afsari, B.; Danilova, L.; Douville, C.; Javed, A.A.; Wong, F.; Mattox, A.; et al. Detection and localization of surgically resectable cancers with a multi-analyte blood test. Science 2018, 359, 926-930. [CrossRef] [PubMed]

44. Siravegna, G.; Marsoni, S.; Siena, S.; Bardelli, A. Integrating liquid biopsies into the management of cancer. Nat. Rev. Clin. Oncol. 2017, 14, 531-548. [CrossRef]

45. AlFakeeh, A.; Brezden-Masley, C. Overcoming Endocrine Resistance in Hormone Receptor-Positive Breast Cancer. Curr. Oncol. 2018, 25, 18-27. [CrossRef]

46. Hanker, A.B.; Sudhan, D.R.; Arteaga, C.L. Overcoming Endocrine Resistance in Breast Cancer. Cancer Cell 2020, $37,496-513$. [CrossRef] [PubMed]

47. Hoefnagel, L.D.; Moelans, C.B.; Meijer, S.L.; van Slooten, H.J.; Wesseling, P.; Wesseling, J.; Westenend, P.J.; Bart, J.; Seldenrijk, C.A.; Nagtegaal, I.D.; et al. Prognostic value of estrogen receptor $\alpha$ and progesterone receptor conversion in distant breast cancer metastases. Cancer 2012, 118, 4929-4935. [CrossRef] [PubMed]

48. Drury, S.C.; Detre, S.; Leary, A.; Salter, J.; Reis-Filho, J.; Barbashina, V.; Marchiò, C.; Lopez-Knowles, E.; Ghazoui, Z.; Habben, K.; et al. Changes in breast cancer biomarkers in the IGF1R/PI3K pathway in recurrent breast cancer after tamoxifen treatment. Endocr. Relat. Cancer 2011, 18, 565-577. [CrossRef] [PubMed]

49. Dodwell, D.; Wardley, A.; Johnston, S. Postmenopausal advanced breast cancer: Options for therapy after tamoxifen and aromatase inhibitors. Breast 2006, 15, 584-594. [CrossRef] [PubMed]

50. Robertson, J.F.; Osborne, C.K.; Howell, A.; Jones, S.E.; Mauriac, L.; Ellis, M.; Kleeberg, U.R.; Come, S.E.; Vergote, I.; Gertler, S.; et al. Fulvestrant versus anastrozole for the treatment of advanced breast carcinoma in postmenopausal women: A prospective combined analysis of two multicenter trials. Cancer 2003, 98, 229-238. [CrossRef]

51. Miller, T.W.; Balko, J.M.; Fox, E.M.; Ghazoui, Z.; Dunbier, A.; Anderson, H.; Dowsett, M.; Jiang, A.; Smith, R.A.; Maira, S.-M.; et al. ER $\alpha$-Dependent E2F Transcription Can Mediate Resistance to Estrogen Deprivation in Human Breast Cancer. Cancer Discov. 2011, 1, 338-351. [CrossRef] [PubMed]

52. Fowler, A.M.; Solodin, N.; Preisler-Mashek, M.T.; Zhang, P.; Lee, A.V.; Alarid, E.T. Increases in estrogen receptor- $\alpha$ concentration in breast cancer cells promote serine 118/104/106-independent AF-1 transactivation and growth in the absence of estrogen. FASEB J. Off. Publ. Fed. Am. Soc. Exp. Biol. 2004, 18, 81-93. [CrossRef] [PubMed]

53. Barone, I.; Brusco, L.; Fuqua, S.A. Estrogen Receptor Mutations and Changes in Downstream Gene Expression and Signaling. Clin. Cancer Res. Off. J. Am. Assoc. Cancer Res. 2010, 16, 2702-2708. [CrossRef]

54. Giordano, C.; Cui, Y.; Barone, I.; Andò, S.; Mancini, M.A.; Berno, V.; Fuqua, S.A. Growth factor-induced resistance to tamoxifen is associated with a mutation of estrogen receptor $\alpha$ and its phosphorylation at serine 305. Breast Cancer Res. Treat. 2010, 119, 71-85. [CrossRef] [PubMed]

55. Gelsomino, L.; Panza, S.; Giordano, C.; Barone, I.; Gu, G.; Spina, E.; Catalano, S.; Fuqua, S.; Andò, S. Mutations in the estrogen receptor alpha hormone binding domain promote stem cell phenotype through notch activation in breast cancer cell lines. Cancer Lett. 2018, 428, 12-20. [CrossRef] [PubMed]

56. Gelsomino, L.; Gu, G.; Rechoum, Y.; Beyer, A.R.; Pejerrey, S.M.; Tsimelzon, A.; Wang, T.; Huffman, K.; Ludlow, A.; Andò, S.; et al. ESR1 mutations affect anti-proliferative responses to tamoxifen through enhanced cross-talk with IGF signaling. Breast Cancer Res. Treat. 2016, 157, 253-265. [CrossRef]

57. Jeselsohn, R.; Buchwalter, G.; De Angelis, C.; Brown, M.; Schiff, R. ESR1 mutations-a mechanism for acquired endocrine resistance in breast cancer. Nat. Rev. Clin. Oncol. 2015, 12, 573-583. [CrossRef] [PubMed]

58. Dustin, D.; Gu, G.; Fuqua, S.A.W. ESR1 mutations in breast cancer. Cancer 2019, 125, 3714-3728. [CrossRef]

59. Schiff, R.; Massarweh, S.; Shou, J.; Osborne, C.K. Breast cancer endocrine resistance: How growth factor signaling and estrogen receptor coregulators modulate response. Clin. Cancer Res. Off. J. Am. Assoc. Cancer Res. 2003, 9, 447S-454S.

60. Jin, K.; Park, S.; Teo, W.W.; Korangath, P.; Cho, S.S.; Yoshida, T.; Győrffy, B.; Goswami, C.P.; Nakshatri, H.; Cruz, L.-A.; et al. HOXB7 Is an ER $\alpha$ Cofactor in the Activation of HER2 and Multiple ER Target Genes Leading to Endocrine Resistance. Cancer Discov. 2015, 5, 944-959. [CrossRef] [PubMed]

61. Bhatt, S.; Stender, J.D.; Joshi, S.; Wu, G.; Katzenellenbogen, B.S. OCT-4: A novel estrogen receptor- $\alpha$ collaborator that promotes tamoxifen resistance in breast cancer cells. Oncogene 2016, 35, 5722-5734. [CrossRef]

62. Schiff, R.; Massarweh, S.A.; Shou, J.; Bharwani, L.; Mohsin, S.K.; Osborne, C.K. Cross-Talk between Estrogen Receptor and Growth Factor Pathways as a Molecular Target for Overcoming Endocrine Resistance. Clin. Cancer Res. Off. J. Am. Assoc. Cancer Res. Clin. Cancer Res. 2004, 10, 331s-336s. [CrossRef] [PubMed]

63. Liu, Y.; El-Ashry, R.; Chen, D.; Ding, I.Y.F.; Kern, F.G. MCF-7 breast cancer cells overexpressing transfectedc-erbB-2 have anin vitro growth advantage in estrogen-depleted conditions and reduced estrogen-dependence and tamoxifen-sensitivity in vivo. Breast Cancer Res. Treat. 1995, 34, 97-117. [CrossRef] 
64. Pietras, R.J.; Arboleda, J.; Reese, D.M.; Wongvipat, N.; Pegram, M.D.; Ramos, L.; Gorman, C.M.; Parker, M.G.; Sliwkowski, M.X.; Slamon, D.J. HER-2 tyrosine kinase pathway targets estrogen receptor and promotes hormone-independent growth in human breast cancer cells. Oncogene 1995, 10, 2435-2446.

65. El-Ashry, D.; Miller, D.L.; Kharbanda, S.; Lippman, M.E.; Kern, F.G. Constitutive Raf-1 kinase activity in breast cancer cells induces both estrogen-independent growth and apoptosis. Oncogene 1997, 15, 423-435. [CrossRef] [PubMed]

66. Luqmani, Y.A.; Alam-Eldin, N. Overcoming Resistance to Endocrine Therapy in Breast Cancer: New Approaches to a Nagging Problem. Med. Princ. Pract. Int. J. Kuwait Univ. Health Sci. Cent. 2016, 25, 28-40. [CrossRef]

67. Creighton, C.J.; Li, X.; Landis, M.; Dixon, J.M.; Neumeister, V.M.; Sjolund, A.; Rimm, D.L.; Wong, H.; Rodriguez, A.; Herschkowitz, J.I.; et al. Residual breast cancers after conventional therapy display mesenchymal as well as tumor-initiating features. Proc. Natl. Acad. Sci. USA 2009, 106, 13820-13825. [CrossRef] [PubMed]

68. Rodriguez, D.; Ramkairsingh, M.; Lin, X.; Kapoor, A.; Major, P.; Tang, D. The Central Contributions of Breast Cancer Stem Cells in Developing Resistance to Endocrine Therapy in Estrogen Receptor (ER)-Positive Breast Cancer. Cancers 2019, 11, 1028. [CrossRef]

69. Selli, C.; Turnbull, A.K.; Pearce, D.A.; Li, A.; Fernando, A.; Wills, J.; Renshaw, L.; Thomas, J.S.; Dixon, J.M.; Sims, A.H. Molecular changes during extended neoadjuvant letrozole treatment of breast cancer: Distinguishing acquired resistance from dormant tumours. Breast Cancer Res. BCR 2019, 21, 2. [CrossRef]

70. Clarke, R.; Tyson, J.J.; Dixon, J.M. Endocrine resistance in breast cancer-An overview and update. Mol. Cell. Endocrinol. 2015, 418, 220-234. [CrossRef]

71. Bussard, K.M.; Mutkus, L.; Stumpf, K.; Gomez-Manzano, C.; Marini, F.C. Tumor-associated stromal cells as key contributors to the tumor microenvironment. Breast Cancer Res. BCR 2016, 18, 84. [CrossRef] [PubMed]

72. Wu, T.; Dai, Y. Tumor microenvironment and therapeutic response. Cancer Lett. 2017, 387, 61-68. [CrossRef]

73. Diaz Bessone, M.I.; Gattas, M.J.; Laporte, T.; Tanaka, M.; Simian, M. The Tumor Microenvironment as a Regulator of Endocrine Resistance in Breast Cancer. Front. Endocrinol. 2019, 10, 547. [CrossRef] [PubMed]

74. Semina, S.E.; Scherbakov, A.M.; Kovalev, S.V.; Shevchenko, V.E.; Krasil'Nikov, M.A. Horizontal Transfer of Tamoxifen Resistance in MCF-7 Cell Derivates: Proteome Study. Cancer Investig. 2017, 35, 506-518. [CrossRef] [PubMed]

75. Semina, S.E.; Scherbakov, A.M.; Vnukova, A.A.; Bagrov, D.V.; Evtushenko, E.G.; Safronova, V.M.; Golovina, D.A.; Lyubchenko, L.N.; Gudkova, M.V.; Krasil'Nikov, M.A. Exosome-Mediated Transfer of Cancer Cell Resistance to Antiestrogen Drugs. Molecules 2018, 23, 829. [CrossRef]

76. Augimeri, G.; La Camera, G.; Gelsomino, L.; Giordano, C.; Panza, S.; Sisci, D.; Morelli, C.; Győrffy, B.; Bonofiglio, D.; Andò, S.; et al. Evidence for Enhanced Exosome Production in Aromatase Inhibitor-Resistant Breast Cancer Cells. Int. J. Mol. Sci. 2020, 21, 5841. [CrossRef]

77. Wei, Y.; Lai, X.; Yu, S.; Chen, S.; Ma, Y.; Zhang, Y.; Li, H.; Zhu, X.; Yao, L.; Zhang, J. Exosomal miR-221/222 enhances tamoxifen resistance in recipient ER-positive breast cancer cells. Breast Cancer Res. Treat. 2014, 147, 423-431. [CrossRef] [PubMed]

78. Sansone, P.; Berishaj, M.; Rajasekhar, V.K.; Ceccarelli, C.; Chang, Q.; Strillacci, A.; Savini, C.; Shapiro, L.; Bowman, R.L.; Mastroleo, C.; et al. Evolution of Cancer Stem-like Cells in Endocrine-Resistant Metastatic Breast Cancers Is Mediated by Stromal Microvesicles. Cancer Res. 2017, 77, 1927-1941. [CrossRef]

79. Xu, C.G.; Yang, M.F.; Ren, Y.Q.; Wu, C.H.; Wang, L.Q. Exosomes mediated transfer of lncRNA UCA1 results in increased tamoxifen resistance in breast cancer cells. Eur. Rev. Med. Pharmacol. Sci. 2016, 20, 4362-4368. [PubMed]

80. Park, M.; Kim, J.; Phuong, N.T.T.; Park, J.G.; Park, J.H.; Kim, Y.C.; Baek, M.C.; Lim, S.C.; Kang, K.W. Involvement of the P2X7 receptor in the migration and metastasis of tamoxifen-resistant breast cancer: Effects on small extracellular vesicles production. Sci. Rep. 2019, 9, 11587. [CrossRef]

81. Sansone, P.; Savini, C.; Kurelac, I.; Chang, Q.; Amato, L.B.; Strillacci, A.; Stepanova, A.; Iommarini, L.; Mastroleo, C.; Daly, L.; et al. Packaging and transfer of mitochondrial DNA via exosomes regulate escape from dormancy in hormonal therapy-resistant breast cancer. Proc. Natl. Acad. Sci. USA 2017, 114, E9066-E9075. [CrossRef] [PubMed]

82. Ciravolo, V.; Huber, V.; Ghedini, G.C.; Venturelli, E.; Bianchi, F.; Campiglio, M.; Morelli, D.; Villa, A.; Della Mina, P.; Menard, S.; et al. Potential role of HER2-overexpressing exosomes in countering trastuzumab-based therapy. J. Cell. Physiol. 2011, 227, 658-667. [CrossRef]

83. Martinez, V.G.; O’Neill, S.; Salimu, J.; Breslin, S.; Clayton, A.; Crown, J.; O’Driscoll, L. Resistance to HER2-targeted anti-cancer drugs is associated with immune evasion in cancer cells and their derived extracellular vesicles. OncoImmunology 2017, 6, e1362530. [CrossRef]

84. Dong, H.; Wang, W.; Chen, R.; Zhang, Y.; Zou, K.; Ye, M.; He, X.; Zhang, F.; Han, J. Exosome-mediated transfer of lncRNA-SNHG14 promotes trastuzumab chemoresistance in breast cancer. Int. J. Oncol. 2018, 53, 1013-1026. [CrossRef]

85. Zheng, Z.; Chen, M.; Xing, P.; Yan, X.; Xie, B. Increased Expression of Exosomal AGAP2-AS1 (AGAP2 Antisense RNA 1) In Breast Cancer Cells Inhibits Trastuzumab-Induced Cell Cytotoxicity. Med. Sci. Monit. Int. Med. J. Exp. Clin. Res. 2019, 25, $2211-2220$. [CrossRef] [PubMed]

86. Han, M.; Gu, Y.; Lu, P.; Li, J.; Cao, H.; Li, X.; Qian, X.; Yu, C.; Yang, Y.; Yang, X.; et al. Exosome-mediated lncRNA AFAP1-AS1 promotes trastuzumab resistance through binding with AUF1 and activating ERBB2 translation. Mol. Cancer 2020, 19, 26. [CrossRef] [PubMed]

87. Han, M.; Hu, J.; Lu, P.; Cao, H.; Yu, C.; Li, X.; Qian, X.; Yang, X.; Yang, Y.; Han, N.; et al. Exosome-transmitted miR-567 reverses trastuzumab resistance by inhibiting ATG5 in breast cancer. Cell Death Dis. 2020, 11, 1-15. [CrossRef] [PubMed] 
88. Cornell, L.; Wander, S.A.; Visal, T.; Wagle, N.; Shapiro, G.I. MicroRNA-Mediated Suppression of the TGF- $\beta$ Pathway Confers Transmissible and Reversible CDK4/6 Inhibitor Resistance. Cell Rep. 2019, 26, 2667-2680.e7. [CrossRef]

89. Valadi, H.; Ekstrom, K.; Bossios, A.; Sjostrand, M.; Lee, J.J.; Lotvall, J.O. Exosome-mediated transfer of mRNAs and microRNAs is a novel mechanism of genetic exchange between cells. Nat. Cell Biol. 2007, 9, 654-659. [CrossRef]

90. Qiu, Y.; Li, W.H.; Zhang, H.Q.; Liu, Y.; Tian, X.X.; Fang, W.G. P2X7 Mediates ATP-Driven Invasiveness in Prostate Cancer Cells. PLoS ONE 2014, 9, e114371. [CrossRef]

91. Slater, M.; Danieletto, S.; Pooley, M.; Cheng Teh, L.; Gidley-Baird, A.; Barden, J.A. Differentiation between Cancerous and Normal Hyperplastic Lobules in Breast Lesions. Breast Cancer Res. Treat. 2004, 83, 1-10. [CrossRef]

92. Xia, J.; Yu, X.; Tang, L.; Li, G.; He, T. P2X7 receptor stimulates breast cancer cell invasion and migration via the AKT pathway. Oncol. Rep. 2015, 34, 103-110. [CrossRef] [PubMed]

93. Brodie, A.; Sabnis, G. Adaptive Changes Result in Activation of Alternate Signaling Pathways and Acquisition of Resistance to Aromatase Inhibitors. Clin. Cancer Res. Off. J. Am. Assoc. Cancer Res. 2011, 17, 4208-4213. [CrossRef]

94. Borg, A.; Baldetorp, B.; Fernö, M.; Killander, D.; Olsson, H.; Ryden, S.; Sigurdsson, H. ERBB2 amplification is associated with tamoxifen resistance in steroid-receptor positive breast cancer. Cancer Lett. 1994, 81, 137-144. [CrossRef]

95. Newby, J.C.; Johnston, S.R.; Smith, I.E.; Dowsett, M. Expression of epidermal growth factor receptor and c-erbB2 during the development of tamoxifen resistance in human breast cancer. Clin. Cancer Res. Off. J. Am. Assoc. Cancer Res. 1997, 3, $1643-1651$.

96. Arpino, G.; Wiechmann, L.; Osborne, C.K.; Schiff, R. Crosstalk between the Estrogen Receptor and the HER Tyrosine Kinase Receptor Family: Molecular Mechanism and Clinical Implications for Endocrine Therapy Resistance. Endocr. Rev. 2008, 29, 217-233. [CrossRef]

97. De Laurentiis, M.; Arpino, G.; Massarelli, E.; Ruggiero, A.; Carlomagno, C.; Ciardiello, F.; Tortora, G.; D’Agostino, D.; Caputo, F.; Cancello, G.; et al. A Meta-Analysis on the Interaction between HER-2 Expression and Response to Endocrine Treatment in Advanced Breast Cancer. Clin. Cancer Res. Off. J. Am. Assoc. Cancer Res. 2005, 11, 4741-4748. [CrossRef]

98. Slamon, D.J.; Godolphin, W.; Jones, L.A.; Holt, J.A.; Wong, S.G.; Keith, D.E.; Levin, W.J.; Stuart, S.G.; Udove, J.; Ullrich, A.; et al. Studies of the HER-2/neu proto-oncogene in human breast and ovarian cancer. Science 1989, 244, 707-712. [CrossRef]

99. Kurokawa, H.; Lenferink, A.E.; Simpson, J.F.; Pisacane, P.I.; Sliwkowski, M.X.; Forbes, J.T.; Arteaga, C.L. Inhibition of HER2/neu (erbB-2) and mitogen-activated protein kinases enhances tamoxifen action against HER2-overexpressing, tamoxifen-resistant breast cancer cells. Cancer Res. 2000, 60, 5887-5894. [PubMed]

100. Osborne, C.K.; Bardou, V.; Hopp, T.A.; Chamness, G.C.; Hilsenbeck, S.G.; Fuqua, S.A.; Wong, J.; Allred, D.C.; Clark, G.M.; Schiff, R. Role of the Estrogen Receptor Coactivator AIB1 (SRC-3) and HER-2/neu in Tamoxifen Resistance in Breast Cancer. J. Natl. Cancer Inst. 2003, 95, 353-361. [CrossRef]

101. Shou, J.; Massarweh, S.; Osborne, C.K.; Wakeling, A.E.; Ali, S.; Weiss, H.; Schiff, R. Mechanisms of Tamoxifen Resistance: Increased Estrogen Receptor-HER2/neu Cross-Talk in ER/HER2-Positive Breast Cancer. J. Natl. Cancer Inst. 2004, 96, 926-935. [CrossRef]

102. Johnston, S.R. Enhancing the Efficacy of Hormonal Agents with Selected Targeted Agents. Clin. Breast Cancer 2009, 9, S28-S36. [CrossRef] [PubMed]

103. Brufsky, A.M.; Dickler, M.N. Estrogen Receptor-Positive Breast Cancer: Exploiting Signaling Pathways Implicated in Endocrine Resistance. Oncologist 2018, 23, 528-539. [CrossRef] [PubMed]

104. Wilcken, N.R.; Prall, O.W.; Musgrove, E.A.; Sutherland, R.L. Inducible overexpression of cyclin D1 in breast cancer cells reverses the growth-inhibitory effects of antiestrogens. Clin. Cancer Res. Off. J. Am. Assoc. Cancer Res. 1997, 3, 849-854.

105. Kilker, R.L.; Planas-Silva, M.D. Cyclin D1 Is Necessary for Tamoxifen-Induced Cell Cycle Progression in Human Breast Cancer Cells. Cancer Res. 2006, 66, 11478-11484. [CrossRef] [PubMed]

106. Thangavel, C.; Dean, J.L.; Ertel, A.; Knudsen, K.E.; Aldaz, C.M.; Witkiewicz, A.K.; Clarke, R.; Knudsen, E.S. Therapeutically activating RB: Reestablishing cell cycle control in endocrine therapy-resistant breast cancer. Endocr. Relat. Cancer 2011, 18, 333-345. [CrossRef]

107. Giordano, S.H.; Elias, A.D.; Gradishar, W.J. NCCN Guidelines Updates: Breast Cancer. J. Natl. Compr. Cancer Netw. 2018, 16, 605-610. [CrossRef] [PubMed]

108. Del Re, M.; Bertolini, I.; Crucitta, S.; Fontanelli, L.; Rofi, E.; De Angelis, C.; Diodati, L.; Cavallero, D.; Gianfilippo, G.; Salvadori, B.; et al. Overexpression of TK1 and CDK9 in plasma-derived exosomes is associated with clinical resistance to CDK4/6 inhibitors in metastatic breast cancer patients. Breast Cancer Res. Treat. 2019, 178, 57-62. [CrossRef] 